Published in final edited form as:

Trends Immunol. 2017 July ; 38(7): 526-536. doi:10.1016/j.it.2017.03.002.

\title{
Immunological functions of the omentum
}

\author{
Selene Meza-Perez and Troy D. Randall ${ }^{\star}$ \\ Department of Medicine, Division of Clinical Immunology and Rheumatology, University of \\ Alabama at Birmingham, Birmingham, AL 35294
}

\begin{abstract}
The omentum is a visceral adipose tissue with unique immune functions. Although it is primarily an adipose tissue, the omentum also contains lymphoid aggregates, called milky spots (MS), that contribute to peritoneal immunity by collecting antigens, particulates and pathogens from the peritoneal cavity and, depending on the stimuli, promoting a variety of immune responses, including inflammation, tolerance or even fibrosis. Reciprocal interactions between cells in the MS and adipocytes regulate their immune and metabolic functions. Importantly, the omentum collects metastasizing tumor cells and supports tumor growth by immunological and metabolic mechanisms. Here we summarize our current knowledge about the development, organization and function of the omentum in peritoneal immunity.
\end{abstract}

\section{Development of the Omentum and Milky Spots}

The omentum is a visceral adipose tissue (VAT) derived from mesothelial cells [1], connected to the spleen, stomach, pancreas and colon [2,3]. Although well known as a visceral fat depot, the role of the omentum in peritoneal immunity wasn't recognized until the early 1900's, when a British surgeon referred to it as "the policeman of the abdomen" due to its ability to attenuate peritonitis and promote surgical wound healing [4]. In fact, the omentum was noted to move about the peritoneal cavity and occlude sites of inflammation, such as ruptured ovaries, inflamed appendices, ulcerated intestines or wounds due to trauma or surgery [4]. Consistent with this observation, the omentum has remarkable angiogenic [5], fibrotic [6], stem cell [7, 8] and immune [9] activities, which together promote vascularization, accelerate wound healing and limit infection. However, these same activities are also likely involved in pathological responses, such as the growth rapid growth of omental tumor metastases [10].

In mice, the omentum is a relatively small strip of fat found anterior and slightly ventral to the stomach [11]. However, in humans the omentum is dramatically larger - reaching an area of $1500 \mathrm{~cm}^{2}$ and resembling an apron that hangs in front of the abdomenal organs [12].

*Correspondence to randallt@uab.edu (T.D. Randall), Department of Medicine, Division of Clinical Immunology and Rheumatology, University of Alabama at Birmingham, $17202^{\text {nd }}$ AVE S, SHEL 507, Birmingham, AL 35294, Phone 205-975-3323, Fax 205-975-3322.

Publisher's Disclaimer: This is a PDF file of an unedited manuscript that has been accepted for publication. As a service to our customers we are providing this early version of the manuscript. The manuscript will undergo copyediting, typesetting, and review of the resulting proof before it is published in its final citable form. Please note that during the production process errors may be discovered which could affect the content, and all legal disclaimers that apply to the journal pertain. 
The omentum in mice is a relatively small fat depot compared to those around the gonads and mesentery, whereas in humans, it is a major depot of abdominal fat. Nevertheless, the omenta of both mice and humans contain Milky Spots (MS), which are aggregates of leukocytes that in many ways resemble the follicles of secondary lymphoid tissues. In this review, we will concentrate on the immune functions of the omentum and the MS and how the activities of these tissues regulate peritoneal immunity.

The MS of the omentum were first described in 1874 in rabbits by the French anatomist, Ranvier, who gave them their name because of their whitish appearance amidst the yellow fat [13]. The MS are organized aggregates of leukocytes embedded between adipocytes just beneath the mesothelial cell layer that covers the omentum (Figure 1). Similar aggregates, known as fat-associated lymphoid clusters (FALCs), are found in other fat depots, including the pericardial and mediastinal fat in the pleural cavity [14-16] as well as the mesenteric fat in the peritoneal cavity $[14,17]$. Although the leukocyte clusters in the omentum and the splenoportal adipose tissue are the only ones known as MS [18, 19], the MS and FALCs are structurally similar, contain similar populations of leukocytes and likely perform similar immune functions. Interestingly, the frequency of MS and FALCs are different depending on the tissue, with the omentum containing the highest frequency of clusters per gram of tissue, followed by the pericardial, mediastinal and mesenteric adipose tissues [14]. Perigonadal fat and subcutaneous fat have few, if any, leukocyte clusters that resemble MS or FALCs.

The MS in the omentum form during fetal development in both humans [20] and mice [14]. Although the development of most secondary lymphoid organs requires lymphotoxin and a subset of innate lymphoid cells (ILCs), known as lymphoid tissue-inducer (LTi) cells, for their development [21], the MS and FALCs do not require these interactions [9, 14]. In fact, MS develop independently of the transcription factors, $\mathrm{ROR} \gamma \mathrm{t}$ and Id2 [9], which are essential for the differentiation of LTi cells and all ILCs, respectively [22]. Interestingly, mesenteric FALCs develop in normal numbers in Rag2-/- mice and Rorc-/- mice, but fail to develop in Rag2-/-II2rg-/- mice [14], demonstrating that some type of innate or adaptive lymphocyte is important for their development. Thus, it is possible that ILC2 cells, which are relatively abundant in adipose tissues [23, 24], functionally replace LTi cells during the development of MS and FALCs.

Exposure to microbiota or microbial products enhances the postnatal maturation of MS and increases the number of observable FALCs in the mesenteric adipose tissue [14].

Conversely, the number of FALCs in the mesenteric fat is reduced by about half in germ-free mice. Moreover, the peritoneal administration of zymosan, a TLR-2-stimulating glucan, promotes the formation of additional FALCs in a process that is dependent on both TNF and CD1d-restricted NKT cells [14]. However, it is not clear whether this increase results from an expansion of previously existing, but very small clusters, or the de novo development of entirely new clusters. Regardless, these data demonstrate that both the primary development and post-natal enhancement of MS and FALCs uses mechanisms distinct from those used by conventional lymphoid organs and suggest that MS and FALCs should be categorized somewhere between true secondary lymphoid organs and tertiary lymphoid tissues. 


\section{Structure of Omental Milky Spots}

The leukocyte clusters in MS are distinctly different from conventional secondary lymphoid tissues. For example, although the leukocytes in MS are supported by a reticular network of fibroblastic stromal cells that can be observed using the ERTR-7 antibody [9], they lack identifiable follicular dendritic cells (FDCs) $[9,25]$. The B cell attracting chemokine, CXCL13, which is associated with FDC networks in conventional lymphoid organs [26], is also strongly expressed in the MS [27]. However, CXCL13 expression in the MS is observed outside the B cell clusters in an area with abundant FDCM1 ${ }^{+} \mathrm{CD} 11 \mathrm{~b}^{+}$cells $[9,27]$. Given that macrophages are a potent source of CXCL13 in the peritoneal cavity and omentum [27], it is likely that these $\mathrm{CD} 11 \mathrm{~b}^{+} \mathrm{CXCL13}{ }^{+}$cells are macrophages. T cells in MS seem to be clustered around blood vessels [9], perhaps HEVs. However, T cells are also found in the B cell area, consistent with the placement of $\mathrm{T}$ follicular helper ( $\mathrm{Tfh}$ ) cells, although bona fide Tfh cells have not yet been identified in MS or FALCs. Despite the presence of both CD4 ${ }^{+}$ and $\mathrm{CD}^{+} \mathrm{T}$ cells [25], it is difficult to discern a well-defined T cell zone. Moreover, it is not clear whether cells with markers of fibroblastic reticular cells (FRCs) are present in MS or whether they are restricted to a particular region. Thus, although MS do have a compartmentalized structure, it is strikingly different than that seen in conventional lymphoid organs.

The omentum as a whole is highly vascularized and the MS in particular are formed around a glomerulus-like knot of blood vessels [25, 28](Figure 1). Some of these vessels express markers of high endothelial venules (HEVs)[9, 25], including peripheral lymph node addressin (PNAd) and mucosal addressin cell adhesion molecule 1 (MAdCAM-1). MAdCAM is typically expressed by HEVs in mucosal lymphoid tissues, such as Peyer's patches and mesenteric lymph nodes [29], but not peripheral lymph nodes, and helps to recruit mucosal-homing lymphocytes from the blood [9, 30]. Not surprisingly, the mucosalassociated integrin, $\alpha 4 \beta 7$, which is the ligand for MAdCAM, is involved in migration from the blood to the omentum $[30,31]$.

The lymphatic architecture of the omentum and MS is also distinct from that in conventional secondary lymphoid organs. For example, lymph nodes collect antigens via afferent lymphatic vessels that deliver cells and antigens to the subcapsular sinus, whereas Peyer's patches and other mucosal lymphoid tissues acquire antigens from mucosal surfaces via specialized M cells in the mucosal epithelium. In contrast, MS lack afferent lymphatics and collect cells and antigens from the peritoneal cavity through fenestrations in the mesothelial layer [9, 28, 31](Figure 1). Efferent lymphatic vessels, on the otherhand, originate around the MS or as a network of endothelial channels between adipocytes [3, 25, 28] and drain towards downstream lymph nodes. In humans, the lymphatic drainage of the omentum empties toward the subpyloric or splenic lymph nodes [32], whereas in mice, the lymphatic drainage empties to the mediastinal or perithymic lymph nodes.

Fluid is continuously drained from the peritoneal cavity, in large part, through the lymphatics of the omentum, carrying with it any free-floating cells, particulates or antigens. As a result, the MS function as filters for the peritoneal fluid, making them ideally situated to generate immune responses to any antigens or pathogens in the peritoneal cavity. Fluid 
flow through the omentum can be increased, for example by peritoneal dialysis, which leads to a dramatic enlargement of the MS and ultimately promotes omental fibrosis [33, 34].

Conversely, tumor cells entrapped by MS form omental metastases that eventually plug the lymphatic drainage and allow the accumulation of ascites fluid in the peritoneal cavity [35].

\section{Cellular Composition of the Omentum and MS}

The leukocyte populations in MS and other FALCs are also quite distinct from those in conventional lymphoid tissues [11,27]. B cells make up the majority of lymphocytes in MS [9]. However, $\operatorname{IgM}^{\text {hi }} \operatorname{IgD}^{\text {lo }} \mathrm{B} 1$ cells outnumber $\operatorname{IgM}^{10} \operatorname{IgD}^{\text {hi }}$ follicular B2 cells in MS, whereas the opposite is true in conventional lymphoid organs [11, 20, 27, 36]. B1 cells are generated by fetal-derived hematopoietic progenitors, some of which contribute to local B1 lymphopoiesis in the omenta of both mice and humans [37, 38]. In adults, self-renewing B1 B cells are maintained in the omentum and peritoneal cavity [27, 37], a process that is dependent on the chemokine CXCL13 [9, 27]. Interestingly, parabiosis studies show that the majority of B1 cells are permanent residents of the omentum and peritoneal cavity [27], whereas the B2 cells in the omentum recirculate between the omentum and other lymphoid tissues.

The omentum also harbors recirculating $\mathrm{CD}^{+}$and $\mathrm{CD} 8^{+} \mathrm{T}$ cells, although at lower frequencies than in conventional lymphoid organs [25]. In contrast, the MS and other FALCs contain higher frequencies of CD1d-restricted NKT cells than conventional lymphoid organs [11]. These NKT cells are depleted (as a fraction of $\mathrm{T}$ cells or of total $\mathrm{CD} 45^{+}$cells) from the omenta of obese humans and those with cancer [39], a finding consistent with observations in obese mice [40]. Interestingly, fat-associated NKT cells are enriched for cells that produce IL-10 [41], suggesting an anti-inflammatory function for these cells. Consistent with this idea, most studies suggest that mice lacking NKT cells gain more weight on a high fat diet, have more inflammatory macrophages in adipose tissue and become insulin resistant [40, 42]. Although these metabolic studies did not test the role of NKT cells specifically in the omentum, the prevalence of these cells in this tissue undoubtedly influences a variety of local immune reactions, such as the expansion of FALCs in response to inflammatory stimuli [14].

The omentum also supports a unique population of VAT-associated $\mathrm{CD} 4^{+}$regulatory $\mathrm{T}$ cells (Tregs)[43], that express the chemokine receptors, CCR1 and CCR2, produce high levels of IL-10, and express proteins like CD36, which is involved in fatty acid metabolism [43, 44]. The phenotype of VAT-associated Tregs is conferred by the transcription factors, PPAR $\gamma$, BATF and IRF4 as well as by IL-33 signaling through ST2 [43, 45]. Although VATassociated Tregs are mostly studied in large fat depots like epididymal fat, which lack MS, they are also found in the omentum [43], where they likely regulate local immune responses. Interestingly, obesity is associated with the loss of VAT-associated Tregs in epididymal fat and a corresponding increase in inflammatory cells and cytokines [43, 44]. Infact, the depletion of VAT-associated Tregs by blockade of the IL-33 receptor, ST2, increases adipose tissue insulin sensitivity [46], suggesting a direct role of Tregs in regulating metabolism. Moreover, in obese mice, the VAT-associated Tregs lose the gene expression signature typical of lean individuals and are less capable of suppressing inflammation [43]. Although 
these data were obtained in fat depots like the epididymal fat, which does not contain MS, VAT-associated Tregs are found in the omentum and are likely important regulators of metabolism and inflammation in this tissue as well.

Innate lymphoid cells (ILCs), particularly ILC2 cells, are also found in adipose tissues, including the omentum [15, 24]. Like VAT-associated Tregs, ILC2 cells express ST2 and respond to local IL-33 [15]. Interestingly, the IL-33-induced expression of IL-5 by ILC2 cells in the FALCs of the pericardium promotes the differentiation of local B1 B cells into IgM-secreting cells [15]. Given that ILC2 cells are also present in the omentum, a similar process likely occurs in this location [47]. ILC2 cells also help regulate metabolic functions. For example, decreases in ILC2 cells in adipose tissue are associated with obesity in both humans and mice [24]. Similar to its role in VAT-associated Tregs, IL-33 is important for the maintenance of ILC2 cells in adipose tissue and in limiting adiposity in mice by increasing caloric expenditure [24]. IL-25 is also implicated in the homeostasis and activation of ILC2 cells in adipose tissue [48]. The administration of IL-25 to obese mice increases ILC 2 cells in VAT and also promotes weight loss and improves glucose tolerance, as does the adoptive transfer of ILC2 cells. Conversely, the depletion of ILC2 cells in obese $\mathrm{Rag} \mathrm{I}^{-/-}$mice promotes weight gain and glucose intolerance [48]. Although the metabolism-regulating activities of ILC2 cells are not limited to the omentum, the omentum is the major depot of abdominal fat in humans and is particularly associated with metabolic disease [49].

Numerous macrophages are found in the omentum under steady-state conditions, although dendritic cells (DCs) are also present in MS [11, 27]. In particular, the omentum and peritoneal cavity hosts a distinctive subset of resident macrophages that is dependent on the transcription factor GATA6 [50]. Interestingly, the GATA6 ${ }^{+}$macrophages express high levels of retinaldehyde dehydrogenase-2 (RALDH2) [50, 51], an enzyme that generates retinoic acid (RA), which is a key factor in isotype-switching to $\operatorname{IgA}[52,53]$. The omentum also maintains macrophage precursors [54], and supports macrophage proliferation [55] via the production of macrophage colony-stimulating factor (M-CSF) by MS stromal cells [56]. Like B1 cells, macrophages are non-circulating residents of the omentum and peritoneal cavity [27]. A subset of peritoneal macrophages is also derived from CCR2-expressing monocyte precursors [57]. The differentiation of these monocyte-derived macrophages is dependent on the transcription factor, IRF4, and requires commensal microbiota [57], again suggesting a connection between the gut and the peritoneal cavity and omentum.

Given the unique populations of Tregs, ILC2 cells, NKT cells and macrophages in the omentum and MS, it is easy to imagine that these cells influence local immune responses, perhaps by dampening inflammatory responses. Other cells, such as B1 cells, seem poised to respond to bacterial antigens and to promote mucosal immunity in the gut. B1 cells also make IL-10 [58] and may contribute to the anti-inflammatory and perhaps tolerogenic environment of the omentum. Consistent with these ideas, the transfer of omental leukocytes from healthy mice to mice with DSS-induced colitis reduces inflammation, promotes healing of the damaged colon, restores body weight and reduces colitis-associated mortality [59]. 


\section{Immune Responses in the Omentum}

Consistent with its ability to collect antigens and cells from the peritoneal cavity, the MS of the omentum support both innate and adaptive immune responses to peritoneal antigens. For example, inflammation in the peritoneal cavity promotes the rapid migration of macrophages to the omentum - a process originally known as the macrophage disappearance reaction [60]. This process can be driven by sterile irritants, including LPS [61], zymosan [14] or thioglycollate [50], as well as inert particles, such as polydextran or silicone beads, which are carried to the omentum by macrophages. All of these stimuli promote the expansion of MS and the production of factors like vascular endothelial growth factor (VEGF) and chemokines like CXCL12 [62-64].

Similar events occur following peritoneal exposure to bacteria. For example, peritoneal administration of attenuated Streptococcus pyogenes triggers the activation of macrophages that engulf the bacteria, home to the omentum and increase both the cellularity and quantity of MS [65]. Importantly, increases in the cellularity of MS are not only driven by the influx of peritoneal cells, but are also due to the recruitment of cells from the blood. In fact, large numbers of circulating neutrophils migrate into the omentum during acute inflammation and sepsis [36]. This process occurs by trafficking across HEVs in the MS and requires PNAd as well as E-selectin, L-selectin and Mac-1 [66].

The inflammation-driven influx of cells from the peritoneal cavity also promotes adaptive immune responses. For example, infection or inflammation-driven production of IL-33 triggers the production of IL- 5 by ILC2 cells, which in turn promotes the differentiation of local B1 cells in the FALCs and MS [15]. Peritoneal administration of LPS also promotes the migration of peritoneal B1 cells to the MS [50,51,61], where they differentiate into IgM-secreting and IgA-secreting cells, some of which colonize the intestine [67, 68], possibly by CXCR4-dependent mechanisms [69]. The omentum also supports the formation and local maintenance of $\operatorname{IgM}^{+}$memory B cells and $\mathrm{CD} 11 \mathrm{c}^{+} \mathrm{IgM}_{\mathrm{g}}$ plasmablasts in response to peritoneal infection [47]. Importantly, LPS-mediated peritoneal inflammation triggers the rapid accumulation of GATA6+ macrophages in the omentum, which produce RA [50, 51], a key factor in isotype switching to IgA [52, 53]. RA also imprints responding B and T cells with gut-homing receptors, such as a $4 \beta 7$ and CCR9 [70, 71]. Surprisingly however, GATA6-dependent macrophages do not imprint a $4 \beta 7$ and CCR9 expression on B cells responding to antigens in the peritoneal cavity and omentum [50].

Despite an obvious focus on B1 responses in the omentum, MS also support B cell germinal center responses to classic T-dependent antigens, such as haptenated OVA, when administered in the peritoneal cavity [9]. However, B cells responding to T-dependent antigens in MS are poorly selected for high-affinity variants [9], consistent with the lack of FDCs in MS. Nevertheless, T-dependent B cell responses in MS lead to high titers of antigen-specific serum IgG [9]. Importantly, these can occur in mice lacking conventional secondary lymphoid organs (Spleen, Lymph node and Peyer's patch-deficient — SLP mice) [47]. Thus, although some might argue that the primary purpose of the MS is to support the rapid differentiation of B1 cells into IgM and IgA-secreting cells, conventional, T-dependent $\mathrm{B}$ cell responses also occur in these sites. 
The MS also support primary responses of conventional $\mathrm{T}$ cells. For instance, the initial activation and first divisions of OVA-specific $\mathrm{CD} 4^{+}$and $\mathrm{CD} 8^{+} \mathrm{T}$ cells occur in the omentum of SLP mice following peritoneal immunization with OVA [9]. Similarly, H-Y-specific CD8 ${ }^{+}$ $\mathrm{T}$ cells are initially activated and proliferate in the omentum before appearing in the peritoneal cavity [31]. Moreover, CD11 $\mathrm{c}^{+} \mathrm{MHCII}{ }^{\mathrm{hi}} \mathrm{DCs}$ from the omentum are potent antigen-presenting cells with the ability to cross-present soluble antigens [31]. About $70 \%$ of these DCs highly express CD11b, whereas about 30\% express CD103 - a ratio consistent with the composition of migratory DCs in a variety of non-lymphoid organs. Importantly, $\mathrm{T}$ cells primed in vitro by DCs from the omentum consistently express a $4 \beta 7$, whereas T cells primed by splenic DCs do not [31], suggesting that omental DCs have mechanisms, such as RALDH2 expression, for promoting the differentiation of mucosal homing T cells. Although these DCs are distinct from GATA6 ${ }^{+}$macrophages, which also express RALDH2 [50], both cell types may promote the differentiation of mucosal homing $\mathrm{T}$ cells or inducible Tregs through the production of RA $[70,72,73]$.

In addition to priming naïve $\mathrm{T}$ cells, the omentum also collects recirculating memory $\mathrm{T}$ cells that are generated at distal sites. For example, mice orally infected with Heligmosomoides polygyrus, a helminth restricted to the gastrointestinal tract [74], accumulate helminthspecific Th2 cells in the peritoneal cavity and omentum [9]. Similarly, mice nasally infected with influenza virus accumulate influenza-specific memory $\mathrm{CD} 4^{+}$and $\mathrm{CD} 8^{+} \mathrm{T}$ cells in the peritoneal cavity and omentum [9]. Both of these responses are mucosal, suggesting that mucosal-homing cells may preferentially home to the omentum. However, a direct comparison with antigen-specific $\mathrm{T}$ cells generated at systemic sites has not been performed.

The omentum and MS clearly have the cell types and immune mechanisms to promote antiinflammatory or tolerogenic responses under steady-state conditions, perhaps as a way to maintain adipocyte homeostasis. The activities of the omentum and MS are also strongly linked to mucosal immunity and IgA production in the gut and may use these same mechanisms and cell types to suppress inflammatory responses to gut antigens and maintain intestinal homeostasis. However, there is no evidence that gut antigens or intestinal DCs are directly sampled by the MS unless the intestine is completely breached - a highly inflammatory and non-homeostatic event! If this is the case, then how do cells in the MS respond to antigens from the gut during homeostasis? (see Outstanding Questions)

\section{Peritoneal Tumor Metastasis in the Omentum}

Primary tumors of the omentum are uncommon. However, the omentum is the most common site of peritoneal metastasis for some tumors, including gastrointestinal and ovarian carcinoma $[28,75,76]$. In particular, ovarian cancer disseminates early and robustly to the omentum, where it is associated with poor prognosis and aggressive growth [10, 77, 78]. Despite the fact that immune responses can be initiated in the MS of the omentum, a protective immune response against tumors seems to not occur and metastatic tumor cells grow progressively [78].

Consistent with studies of inert antigens in the peritoneal cavity, live tumor cells injected into the peritoneal cavity are trapped in the MS $[9,28]$ - a finding that is consistent for 
multiple tumor cell lines, including B16 melanoma, ID8 ovarian carcinoma, EG7 lymphoma, MC38 colon carcinoma, gastric carcinoma and EMT6 lung carcinoma [28, 79]. In each of these cases, tumor cells initially colonize the MS before being observed in nonMS areas of the omentum. In some cases, this phenomenon is attributed to the selective recruitment of CCR4-expressing tumor cells to CCL22-expressing macrophages in the MS [80]. However, the accumulation of tumor cells in the MS is not necessarily dependent on chemotaxis, as pertussis toxin-treated EL4 cells administered to the peritoneal cavity accumulate in the MS just as rapidly as untreated cells [9]. Thus, although chemokinedependent migration of tumor cells to the omentum and MS undoubtedly occurs for some tumor cells, they can also accumulate passively due to fluid flow from the peritoneal cavity through the MS and omentum.

Although the omentum efficiently collects tumor cells from the peritoneal cavity, ovarian tumor cells circulating in the blood also preferentially metastasize to the omentum. In fact, a recent study shows that parabiotic joining of a tumor-bearing mouse with a non-tumorbearing mouse leads to ovarian tumor metastasis to the partner omentum [81]. Given that parabiotic mice have a joint circulation, but independent lymphatic systems, this study shows a metastatic preference for the omentum, even when tumor cells are freely circulating throughout the body [81]. In part, this preference can be attributed to ErbB2, also known as HER2/neu, a member of the epidermal growth factor receptor family [81], which is expressed by tumor cells, and its ligand, neuregulin 1 (NRG1), which is expressed by unknown cell types surrounding the omental vasculature. A similar phenomenon may occur in humans, in which an increase in ErbB2 expression in ovarian carcinoma cells correlates with advanced staging of the tumors [81]. Ovarian cancer cells also stimulate omental fibroblast proliferation via transforming growth factor (TGF)- $\beta 1$, which facilitates tumor cell implantation and subsequent dissemination [82]. Tumor cell implantation in the MS also promotes local angiogenesis due to the production of VEGF-C [79] and VEGF-A [28] by mesothelial cells. An additional explanation for the preferential tumor growth in omentum in ovarian cancer is attributed to the adipocytes themselves. Adipocytes express fatty-acid binding proteins (FABP)[83], including FABP4, which promotes lipid transfer from adipocytes to tumor cells and facilitates $\beta$-oxidation metabolism in tumor cells, thereby enhancing their proliferation and invasiveness [84]. Thus, the omentum is an ideal environment for tumor cell metastasis and subsequent growth.

How does the immune activity of leukocytes in the MS impact tumor growth? The initial colonization of tumor cells triggers an increase in MS size and number, mainly by macrophage recruitment from the peritoneal cavity [65]. Despite this apparent activation, the tumor cells continue to grow [76, 78], suggesting a lack of immune recognition or perhaps a potent immune-suppressive effect. Nevertheless, there are indications that ovarian cancer can be recognized by the immune system [85]. For example, the presence of tumor infiltrating lymphocytes (TILs), particularly CD $8^{+} \mathrm{T}$ cells, in both primary tumors (ovary) and metastatic tumors (omentum), positively correlates with overall survival $[86,87]$, whereas the absence of TILs correlates with treatment failure. Similarly, patients whose tumors have gene expression signatures of $\mathrm{CD} 8^{+} \mathrm{T}$ cells and antigen presentation pathways have a good prognosis $[88,89]$. Conversely, the presence of Tregs in both malignant ascites and tumor mass is associated with poor outcomes [90]. 
The VEGF-driven accumulation of CD33+ ${ }^{+}$myeloid-derived suppressor cells (MDSCs), particularly in the omentum, also correlates with a failure to accumulate $\mathrm{CD} 8^{+} \mathrm{TILs}$, the suppression of $\mathrm{T}$ cell function and a poor prognosis in ovarian cancer patients [91]. Similarly, $\mathrm{CD}_{3}{ }^{+}$MDSCs that accumulate in peritoneal ascites fluid of ovarian cancer patients express nitric oxide synthase-2 (NOS2) and produce NO [92], which promotes the differentiation of Th17 cells and impairs the function of Th1 and CD8 $8^{+} \mathrm{T}$ cells. Although Th17 responses can in some cases promote anti-tumor immunity [93], chronic IL-17-driven inflammation is also associated with tumorigenesis [94]. Thus, a feed-forward loop between Th17 cells and MDSCs in the peritoneal cavity and omentum is likely a driver of ovarian cancer metastasis and progression.

Given our understanding of the immune activities of the omentum and MS, it seems reasonable to devise immune strategies to target these sites and benefit local anti-tumor immunity. For example, phagocytic cells in the omentum can be targeted with antigenloaded, oligomannose-coated liposomes, which promote tumor-antigen-specific $\mathrm{CD} 8^{+} \mathrm{T}$ cell responses and impair tumor growth [95]. Similarly, peritoneal vaccination with lethally irradiated tumor cells leads to a local NK-mediated immune response in the MS that impairs subsequent tumor growth [96]. Consistent with the immune suppressive properties of the omentum, TILs from human ovarian tumor fragments grafted in the omentum of immunodeficient mice are anergic [97]. However, the administration of IL-12 loaded liposomes promotes local $\mathrm{T}$ cell reactivation, impairs tumor growth and prolongs survival [97]. In addition to immunological interventions, physicians now use intraperitoneal chemotherapy to increase overall survival in ovarian cancer patients [98], although the role of the omentum or MS is unclear at this time. Together, these studies suggest that therapies that target antigens or drugs to the omentum may be important for controlling peritoneal tumors. However, surgeons often resect most or all of the omentum in the context of ovarian cancer to eliminate as much metastatic disease as possible [77, 78].

Interestingly, omentectomy is also used in combination with gastric bypass surgery to promote weight loss and reduce symptoms of metabolic syndrome [99-101]. Although some studies suggest that omentectomy lowers inflammatory markers in skeletal muscle [99], and reduces C-reactive protein in serum [102], more recent trials find that omentectomy provides no additional benefit over gastric bypass alone with regards to metabolic parameters [100, 101]. These data may suggest a differential role of the omentum in regulating inflammatory and metabolic processes, perhaps due to its immune functions. Unfortunately, we have no information on peritoneal immune responses following omentectomy in patients with obesity or ovarian cancer.

\section{Concluding Remarks}

We now understand that the immune activity of the omentum is highly specialized and that its unusual leukocyte composition is likely evolved to maintain adipocyte homeostasis, protect the unique environment of the peritoneal cavity and promote the differentiation of mucosal-homing cells that recognize gut antigens. Importantly, this model suggests that perturbations of omental functions that may occur in the context of obesity, tumor metastasis, peritoneal dialysis or most extremely, omentectomy, may also have unpredictable 
effects on immune regulation in the gut and peritoneal cavity, the progression of metabolic disease, tumor progression or even systemic inflammation. Thus, the omentum is an immunologically important, albeit poorly understood and often overlooked, regulator of regional immune responses.

\section{Acknowledgments}

This work was supported by NIH grant RO1-CA216234 to TDR and by the UAB Comprehensive Cancer Center P30-CA013148.

\section{Glossary}

\section{Omentum}

The omentum is a specialized adipose tissue in the peritoneal cavity that is connected by a mesothelial layer to the spleen, stomach, transverse colon and pancreas. In mice it appears as a thin strip of fat, whereas in humans the omentum is an apron-like sheet that hangs in front of the visceral organs

\section{Milky spots (MS)}

MS are clusters of leukocytes embedded in adipose tissue, primarily in the omentum and the splenic-portal fat. They function similar to lymph nodes, in that they collect and respond to local antigens. However, the cellular composition of MS more closely resembles the cells in the peritoneal cavity than cells in conventional secondary lymphoid organs like lymph nodes and spleen

\section{Fat-Associated lymphoid clusters (FALCs)}

FALCs are similar to MS in that they are clusters of leukocytes embedded in adipose tissue, primarily in mesenteric and pleural fat. However, FALCs are partially dependent on microbiota for their formation and are smaller and less frequent than the MS of the omentum. Their function may be similar

\section{Visceral adipose tissue (VAT)-associated Tregs}

VAT-associated Tregs are a subset of FoxP3+ Tregs that reside in adipose tissue, including the omentum. These cells depend on the transcription factor, PPAR $\gamma$, that is normally associated with adipocyte differentiation. They are found in perigonadal fat, which lacks MS or FALCs

\section{Mesothelial cells}

Mesothelial cells are a thin layer of cells that covers the omentum and other visceral and pleural organs. The surface of mesothelial cells is slippery to reduce friction between organs. Mesothelail cells are a potent source of TGFb in the omentum

\section{SLP mice}

Spleen, Lymph node and Peyer's patch-deficient mice are generated by surgically removing the spleen from lymphotoxin-deficient mice (which lack lymph nodes and Peyer's patches) and irradiating splenectomized $\mathrm{Lta}^{-/-}$mice and reconstituting them with WT BM. The omentum and MS remain in these mice, allowing investigators to isolate their activity from other lymphoid organs 


\section{Parabiosis}

Parabiosis is a surgical technique in which two mice, usually expressing distinct markers, are surgically joined by the skin, side-by-side, so that they share a circulation. This technique allows cells in the blood to circulate between the joined animals, and is used to analyze whether cells are circulating or resident (based on the presence of cells with both markers, or the host alone, respectively)

\section{References}

1. Chau YY, et al. Visceral and subcutaneous fat have different origins and evidence supports a mesothelial source. Nat Cell Biol. 2014; 16(4):367-75. [PubMed: 24609269]

2. Williams R, White $H$. The greater omentum: its applicability to cancer surgery and cancer therapy. Curr Probl Surg. 1986; 23(11):789-865. [PubMed: 3780294]

3. Wilkosz S, et al. A comparative study of the structure of human and murine greater omentum. Anat Embryol (Berl). 2005; 209(3):251-61. [PubMed: 15662530]

4. Morrison R. On the functional aspects of the greater omentum. British Medical Journal. 1906; 1:7678. [PubMed: 20762478]

5. Garcia-Gomez I, et al. Angiogenic capacity of human omental stem cells. Neurol Res. 2005; 27(8): 807-11. [PubMed: 16354540]

6. Divoux A, et al. Fibrosis in human adipose tissue: composition, distribution, and link with lipid metabolism and fat mass loss. Diabetes. 2010; 59(11):2817-25. [PubMed: 20713683]

7. Shah S, et al. Cellular basis of tissue regeneration by omentum. PLoS One. 2012; 7(6):e38368. [PubMed: 22701632]

8. Russo V, et al. Comparison of human adipose-derived stem cells isolated from subcutaneous, omental, and intrathoracic adipose tissue depots for regenerative applications. Stem Cells Transl Med. 2014; 3(2):206-17. [PubMed: 24361924]

9. Rangel-Moreno J, et al. Omental milky spots develop in the absence of lymphoid tissue-inducer cells and support B and T cell responses to peritoneal antigens. Immunity. 2009; 30(5):731-43. [PubMed: 19427241]

10. Koppe MJ, et al. Recent insights into the pathophysiology of omental metastases. J Surg Oncol. 2014; 110(6):670-5. [PubMed: 24962271]

11. Cohen $\mathrm{CA}$, et al. Intra-abdominal fat depots represent distinct immunomodulatory microenvironments: a murine model. PLoS One. 2013; 8(6):e66477. [PubMed: 23776677]

12. Platell C, et al. The omentum. World J Gastroenterol. 2000; 6(2):169-176. [PubMed: 11819552]

13. Ranvier I. Du développement et de l'accroissement des vaisseaux sanguins. Arch Physiol Norm Path. 1874; 6:429-449.

14. Benezech $\mathrm{C}$, et al. Inflammation-induced formation of fat-associated lymphoid clusters. Nat Immunol. 2015; 16(8):819-28. [PubMed: 26147686]

15. Jackson-Jones LH, et al. Fat-associated lymphoid clusters control local IgM secretion during pleural infection and lung inflammation. Nat Commun. 2016; 7:12651. [PubMed: 27582256]

16. Elewa YH, et al. Characterization of mouse mediastinal fat-associated lymphoid clusters. Cell Tissue Res. 2014; 357(3):731-41. [PubMed: 24853670]

17. Moro K, et al. Innate production of $\mathrm{T}(\mathrm{H}) 2$ cytokines by adipose tissue-associated c-Kit(+)Sca-1(+) lymphoid cells. Nature. 2010; 463(7280):540-4. [PubMed: 20023630]

18. Clark R, et al. Milky spots promote ovarian cancer metastatic colonization of peritoneal adipose in experimental models. Am J Pathol. 2013; 183(2):576-91. [PubMed: 23885715]

19. Takemori N, et al. Light and electron microscope study of splenoportal milky spots in New Zealand black mice: comparison between splenoportal milky spots and aberrant spleens. J Anat. 1995; 186(Pt 2):287-99. [PubMed: 7649827]

20. Krist LF, et al. Ontogeny of milky spots in the human greater omentum: an immunochemical study. Anat Rec. 1997; 249(3):399-404. [PubMed: 9372174] 
21. Cupedo T, Mebius RE. Cellular interactions in lymph node development. J Immunol. 2005; 174(1): 21-5. [PubMed: 15611222]

22. Spits H, Cupedo T. Innate lymphoid cells: emerging insights in development, lineage relationships, and function. Annu Rev Immunol. 2012; 30:647-75. [PubMed: 22224763]

23. Lee MW, et al. Activated type 2 innate lymphoid cells regulate beige fat biogenesis. Cell. 2015; 160(1-2):74-87. [PubMed: 25543153]

24. Brestoff JR, et al. Group 2 innate lymphoid cells promote beiging of white adipose tissue and limit obesity. Nature. 2015; 519(7542):242-6. [PubMed: 25533952]

25. Shimotsuma M, et al. Morpho-physiological function and role of omental milky spots as omentumassociated lymphoid tissue (OALT) in the peritoneal cavity. Lymphology. 1993; 26(2):90-101. [PubMed: 8355522]

26. Cyster JG, et al. Follicular stromal cells and lymphocyte homing to follicles. Immunol Rev. 2000; 176:181-93. [PubMed: 11043777]

27. Ansel KM, et al. CXCL13 is required for B1 cell homing, natural antibody production, and body cavity immunity. Immunity. 2002; 16(1):67-76. [PubMed: 11825566]

28. Gerber SA, et al. Preferential attachment of peritoneal tumor metastases to omental immune aggregates and possible role of a unique vascular microenvironment in metastatic survival and growth. Am J Pathol. 2006; 169(5):1739-52. [PubMed: 17071597]

29. Briskin M, et al. Human mucosal addressin cell adhesion molecule-1 is preferentially expressed in intestinal tract and associated lymphoid tissue. Am J Pathol. 1997; 151(1):97-110. [PubMed: 9212736]

30. Berberich S, et al. Differential molecular and anatomical basis for B cell migration into the peritoneal cavity and omental milky spots. J Immunol. 2008; 180(4):2196-203. [PubMed: 18250426]

31. Carlow DA, et al. Lymphocytes in the peritoneum home to the omentum and are activated by resident dendritic cells. J Immunol. 2009; 183(2):1155-65. [PubMed: 19553538]

32. Liebermann-Meffert D. The greater omentum. Anatomy, embryology, and surgical applications. Surg Clin North Am. 2000; 80(1):275-93. xii. [PubMed: 10685153]

33. Beelen RH, et al. Rat models in peritoneal dialysis. Nephrol Dial Transplant. 2001; 16(3):672-4. [PubMed: 11239066]

34. Beelen RH, et al. Omental milky spots in peritoneal pathophysiology (spots before your eyes). Perit Dial Int. 2005; 25(1):30-2. [PubMed: 15770922]

35. Sangisetty SL, Miner TJ. Malignant ascites: A review of prognostic factors, pathophysiology and therapeutic measures. World J Gastrointest Surg. 2012; 4(4):87-95. [PubMed: 22590662]

36. Van Vugt E, et al. Omental milky spots in the local immune response in the peritoneal cavity of rats. Anat Rec. 1996; 244(2):235-45. [PubMed: 8808398]

37. Solvason N, et al. The fetal omentum in mice and humans. A site enriched for precursors of CD5 B cells early in development. Ann N Y Acad Sci. 1992; 651:10-20. [PubMed: 1376027]

38. Solvason N, Kearney JF. The human fetal omentum: a site of B cell generation. J Exp Med. 1992; 175(2):397-404. [PubMed: 1370683]

39. Lynch L, et al. Invariant NKT cells and CD1d(+) cells amass in human omentum and are depleted in patients with cancer and obesity. Eur J Immunol. 2009; 39(7):1893-901. [PubMed: 19585513]

40. Lynch L, et al. Adipose tissue invariant NKT cells protect against diet-induced obesity and metabolic disorder through regulatory cytokine production. Immunity. 2012; 37(3):574-87. [PubMed: 22981538]

41. Sag D, et al. IL-10-producing NKT10 cells are a distinct regulatory invariant NKT cell subset. J Clin Invest. 2014; 124(9):3725-40. [PubMed: 25061873]

42. Ji Y, et al. Activation of natural killer T cells promotes M2 Macrophage polarization in adipose tissue and improves systemic glucose tolerance via interleukin-4 (IL-4)/STAT6 protein signaling axis in obesity. J Biol Chem. 2012; 287(17):13561-71. [PubMed: 22396530]

43. Cipolletta D, et al. Appearance and disappearance of the mRNA signature characteristic of Treg cells in visceral adipose tissue: age, diet, and PPARgamma effects. Proc Natl Acad Sci U S A. 2015; 112(2):482-7. [PubMed: 25550516] 
44. Feuerer M, et al. Lean, but not obese, fat is enriched for a unique population of regulatory $\mathrm{T}$ cells that affect metabolic parameters. Nat Med. 2009; 15(8):930-9. [PubMed: 19633656]

45. Vasanthakumar A, et al. The transcriptional regulators IRF4, BATF and IL-33 orchestrate development and maintenance of adipose tissue-resident regulatory T cells. Nat Immunol. 2015; 16(3):276-85. [PubMed: 25599561]

46. Bapat SP, et al. Depletion of fat-resident Treg cells prevents age-associated insulin resistance. Nature. 2015; 528(7580):137-41. [PubMed: 26580014]

47. Jones DD, et al. The omentum is a site of protective IgM production during intracellular bacterial infection. Infect Immun. 2015; 83(5):2139-47. [PubMed: 25776744]

48. Hams E, et al. Cutting edge: IL-25 elicits innate lymphoid type 2 and type II NKT cells that regulate obesity in mice. J Immunol. 2013; 191(11):5349-53. [PubMed: 24166975]

49. Wajchenberg BL, et al. Depot-specific hormonal characteristics of subcutaneous and visceral adipose tissue and their relation to the metabolic syndrome. Horm Metab Res. 2002; 34(11-12): 616-21. [PubMed: 12660870]

50. Okabe Y, Medzhitov R. Tissue-specific signals control reversible program of localization and functional polarization of macrophages. Cell. 2014; 157(4):832-44. [PubMed: 24792964]

51. Maruya M, et al. Vitamin A-dependent transcriptional activation of the nuclear factor of activated T cells c1 (NFATc1) is critical for the development and survival of B1 cells. Proc Natl Acad Sci U S A. 2011; 108(2):722-7. [PubMed: 21187378]

52. Mora JR, von Andrian UH. Differentiation and homing of IgA-secreting cells. Mucosal Immunol. 2008; 1(2):96-109. [PubMed: 19079167]

53. Mora JR, von Andrian UH. Role of retinoic acid in the imprinting of gut-homing IgA-secreting cells. Semin Immunol. 2009; 21(1):28-35. [PubMed: 18804386]

54. Daems WT, de Bakker JM. Do resident macrophages proliferate? Immunobiology. 1982; 161(3-4): 204-11. [PubMed: 7047370]

55. Wijffels JF, et al. Milky spots in the mouse omentum may play an important role in the origin of peritoneal macrophages. Res Immunol. 1992; 143(4):401-9. [PubMed: 1518954]

56. Ratajczak MZ, et al. Omental lymphoid organ as a source of macrophage colony stimulating activity in peritoneal cavity. Clin Exp Immunol. 1987; 69(1):198-203. [PubMed: 3498587]

57. Kim KW, et al. MHC II+ resident peritoneal and pleural macrophages rely on IRF4 for development from circulating monocytes. J Exp Med. 2016; 213(10):1951-9. [PubMed: 27551152]

58. O'Garra A, Howard M. IL-10 production by CD5 B cells. Ann N Y Acad Sci. 1992; 651:182-99. [PubMed: 1376039]

59. Jung BC, et al. Omentum Cells Promote Healing of Colonic Tissues in Dextran Sulfate Sodium (DSS) Induced Model of Colitis in Mice. J Lifestyle Med. 2013; 3(1):48-53. [PubMed: 26064837]

60. Barth MW, et al. Review of the macrophage disappearance reaction. J Leukoc Biol. 1995; 57(3): 361-7. [PubMed: 7884305]

61. Ha SA, et al. Regulation of B1 cell migration by signals through Toll-like receptors. J Exp Med. 2006; 203(11):2541-50. [PubMed: 17060475]

62. Litbarg NO, et al. Activated omentum becomes rich in factors that promote healing and tissue regeneration. Cell Tissue Res. 2007; 328(3):487-97. [PubMed: 17468892]

63. Saqib NU, et al. The omentum is a site of stromal cell-derived factor 1alpha production and reservoir for CXC chemokine receptor 4-positive cell recruitment. Am J Surg. 2010; 200(2):27682. [PubMed: 20591406]

64. Zhang QX, et al. Vascular endothelial growth factor is the major angiogenic factor in omentum: mechanism of the omentum-mediated angiogenesis. J Surg Res. 1997; 67(2):147-54. [PubMed: 9073561]

65. Shimotsuma M, et al. Activation of omental milky spots and milky spot macrophages by intraperitoneal administration of a streptococcal preparation, OK-432. Cancer Res. 1992; 52(19): 5400-2. [PubMed: 1394145]

66. Buscher K, et al. Protection from septic peritonitis by rapid neutrophil recruitment through omental high endothelial venules. Nat Commun. 2016; 7:10828. [PubMed: 26940548] 
67. Fagarasan $\mathrm{S}$, et al. Adaptive immune regulation in the gut: $\mathrm{T}$ cell-dependent and $\mathrm{T}$ cell-independent IgA synthesis. Annu Rev Immunol. 2010; 28:243-73. [PubMed: 20192805]

68. Suzuki K, et al. Roles of B-1 and B-2 cells in innate and acquired IgA-mediated immunity. Immunol Rev. 2010; 237(1):180-90. [PubMed: 20727036]

69. Moon H, et al. LPS-induced migration of peritoneal B-1 cells is associated with upregulation of CXCR4 and increased migratory sensitivity to CXCL12. J Korean Med Sci. 2012; 27(1):27-35. [PubMed: 22219610]

70. Liu ZM, et al. The role of all-trans retinoic acid in the biology of Foxp3+ regulatory T cells. Cell Mol Immunol. 2015; 12(5):553-7. [PubMed: 25640656]

71. Bono MR, et al. Retinoic Acid as a Modulator of T Cell Immunity. Nutrients. 2016; 8(6)

72. Mucida D, et al. Reciprocal TH17 and regulatory T cell differentiation mediated by retinoic acid. Science. 2007; 317(5835):256-60. [PubMed: 17569825]

73. Benson MJ, et al. All-trans retinoic acid mediates enhanced $\mathrm{T}$ reg cell growth, differentiation, and gut homing in the face of high levels of co-stimulation. J Exp Med. 2007; 204(8):1765-74. [PubMed: 17620363]

74. Reynolds LA, et al. Immunity to the model intestinal helminth parasite Heligmosomoides polygyrus. Semin Immunopathol. 2012; 34(6):829-46. [PubMed: 23053394]

75. Hagiwara A, et al. Milky spots as the implantation site for malignant cells in peritoneal dissemination in mice. Cancer Res. 1993; 53(3):687-92. [PubMed: 8425204]

76. Krist LF, et al. Milky spots in the greater omentum are predominant sites of local tumour cell proliferation and accumulation in the peritoneal cavity. Cancer Immunol Immunother. 1998; 47(4): 205-12. [PubMed: 9875673]

77. Arie AB, et al. The omentum and omentectomy in epithelial ovarian cancer: a reappraisal: part IIThe role of omentectomy in the staging and treatment of apparent early stage epithelial ovarian cancer. Gynecol Oncol. 2013; 131(3):784-90. [PubMed: 24056005]

78. Oosterling SJ, et al. Insufficient ability of omental milky spots to prevent peritoneal tumor outgrowth supports omentectomy in minimal residual disease. Cancer Immunol Immunother. 2006; 55(9):1043-51. [PubMed: 16311732]

79. Sorensen EW, et al. Omental immune aggregates and tumor metastasis within the peritoneal cavity. Immunol Res. 2009; 45(2-3):185-94. [PubMed: 19253004]

80. Cao L, et al. The role of the CCL22-CCR4 axis in the metastasis of gastric cancer cells into omental milky spots. J Transl Med. 2014; 12:267. [PubMed: 25245466]

81. Pradeep S, et al. Hematogenous metastasis of ovarian cancer: rethinking mode of spread. Cancer Cell. 2014; 26(1):77-91. [PubMed: 25026212]

82. Cai J, et al. Fibroblasts in omentum activated by tumor cells promote ovarian cancer growth, adhesion and invasiveness. Carcinogenesis. 2012; 33(1):20-9. [PubMed: 22021907]

83. Shan T, et al. Fatty acid binding protein 4 expression marks a population of adipocyte progenitors in white and brown adipose tissues. FASEB J. 2013; 27(1):277-87. [PubMed: 23047894]

84. Nieman KM, et al. Adipocytes promote ovarian cancer metastasis and provide energy for rapid tumor growth. Nat Med. 2011; 17(11):1498-503. [PubMed: 22037646]

85. Zhang L, et al. Intratumoral T cells, recurrence, and survival in epithelial ovarian cancer. N Engl J Med. 2003; 348(3):203-13. [PubMed: 12529460]

86. Wouters MC, et al. Treatment Regimen, Surgical Outcome, and T-cell Differentiation Influence Prognostic Benefit of Tumor-Infiltrating Lymphocytes in High-Grade Serous Ovarian Cancer. Clin Cancer Res. 2016; 22(3):714-24. [PubMed: 26384738]

87. Sato E, et al. Intraepithelial CD8+ tumor-infiltrating lymphocytes and a high CD8+/regulatory T cell ratio are associated with favorable prognosis in ovarian cancer. Proc Natl Acad Sci U S A. 2005; 102(51):18538-43. [PubMed: 16344461]

88. Cancer Genome Atlas Research, N. Integrated genomic analyses of ovarian carcinoma. Nature. 2011; 474(7353):609-15. [PubMed: 21720365]

89. Tothill RW, et al. Novel molecular subtypes of serous and endometrioid ovarian cancer linked to clinical outcome. Clin Cancer Res. 2008; 14(16):5198-208. [PubMed: 18698038] 
90. Curiel TJ, et al. Specific recruitment of regulatory T cells in ovarian carcinoma fosters immune privilege and predicts reduced survival. Nat Med. 2004; 10(9):942-9. [PubMed: 15322536]

91. Horikawa N, et al. Expression of Vascular Endothelial Growth Factor in Ovarian Cancer Inhibits Tumor Immunity through the Accumulation of Myeloid-Derived Suppressor Cells. Clin Cancer Res. 2017; 23(2):587-599. [PubMed: 27401249]

92. Obermajer N, et al. Induction and stability of human Th17 cells require endogenous NOS 2 and cGMP-dependent NO signaling. J Exp Med. 2013; 210(7):1433-445. [PubMed: 23797095]

93. Viaud $\mathrm{S}$, et al. The intestinal microbiota modulates the anticancer immune effects of cyclophosphamide. Science. 2013; 342(6161):971-6. [PubMed: 24264990]

94. Asquith M, Powrie F. An innately dangerous balancing act: intestinal homeostasis, inflammation, and colitis-associated cancer. J Exp Med. 2010; 207(8):1573-7. [PubMed: 20679404]

95. Ikehara Y, et al. Effective induction of anti-tumor immune responses with oligomannose-coated liposome targeting to intraperitoneal phagocytic cells. Cancer Lett. 2008; 260(1-2):137-45. [PubMed: 18077084]

96. Sedlacek AL, et al. Generation of a dual-functioning antitumor immune response in the peritoneal cavity. Am J Pathol. 2013; 183(4):1318-28. [PubMed: 23933065]

97. Yokota SJ, et al. Changes in ovarian tumor cell number, tumor vasculature, and T cell function monitored in vivo using a novel xenograft model. Cancer Immun. 2013; 13:11. [PubMed: 23885217]

98. Armstrong DK, et al. Intraperitoneal cisplatin and paclitaxel in ovarian cancer. N Engl J Med. 2006; 354(1):34-43. [PubMed: 16394300]

99. Tamboli RA, et al. Reduction in inflammatory gene expression in skeletal muscle from Roux-en-Y gastric bypass patients randomized to omentectomy. PLoS One. 2011; 6(12):e28577. [PubMed: 22194858]

100. Andersson DP, et al. Omentectomy in Addition to Bariatric Surgery-a 5-Year Follow-up. Obes Surg. 2017; 27(4):1115-1118. [PubMed: 28155057]

101. Sdralis E, et al. A prospective randomized study comparing patients with morbid obesity submitted to sleeve gastrectomy with or without omentectomy. Obes Surg. 2013; 23(7):965-71. [PubMed: 23526069]

102. Lima MM, et al. Visceral fat resection in humans: effect on insulin sensitivity, beta-cell function, adipokines, and inflammatory markers. Obesity (Silver Spring). 2013; 21(3):E182-9. [PubMed: 23404948] 


\section{Trends box}

VAT-associated Tregs are a transcriptionally and functionally unique population of Tregs that regulate immune responses and metabolic process in adipose tissues, including the omentum.

ILC2 cells are found in adipose tissues like the omentum, where they regulate local immune responses and adipocyte metabolism

The omentum is a well characterized site of ovarian cancer metastasis due to its ability to collect tumor cells from the peritoneal cavity and to support tumor cell metabolism and growth

Despite the immune functions of the omentum, it appears unable to promote adaptive immune response to tumors that implant in the milky spots. 
A

Mouse omentum Milky spots

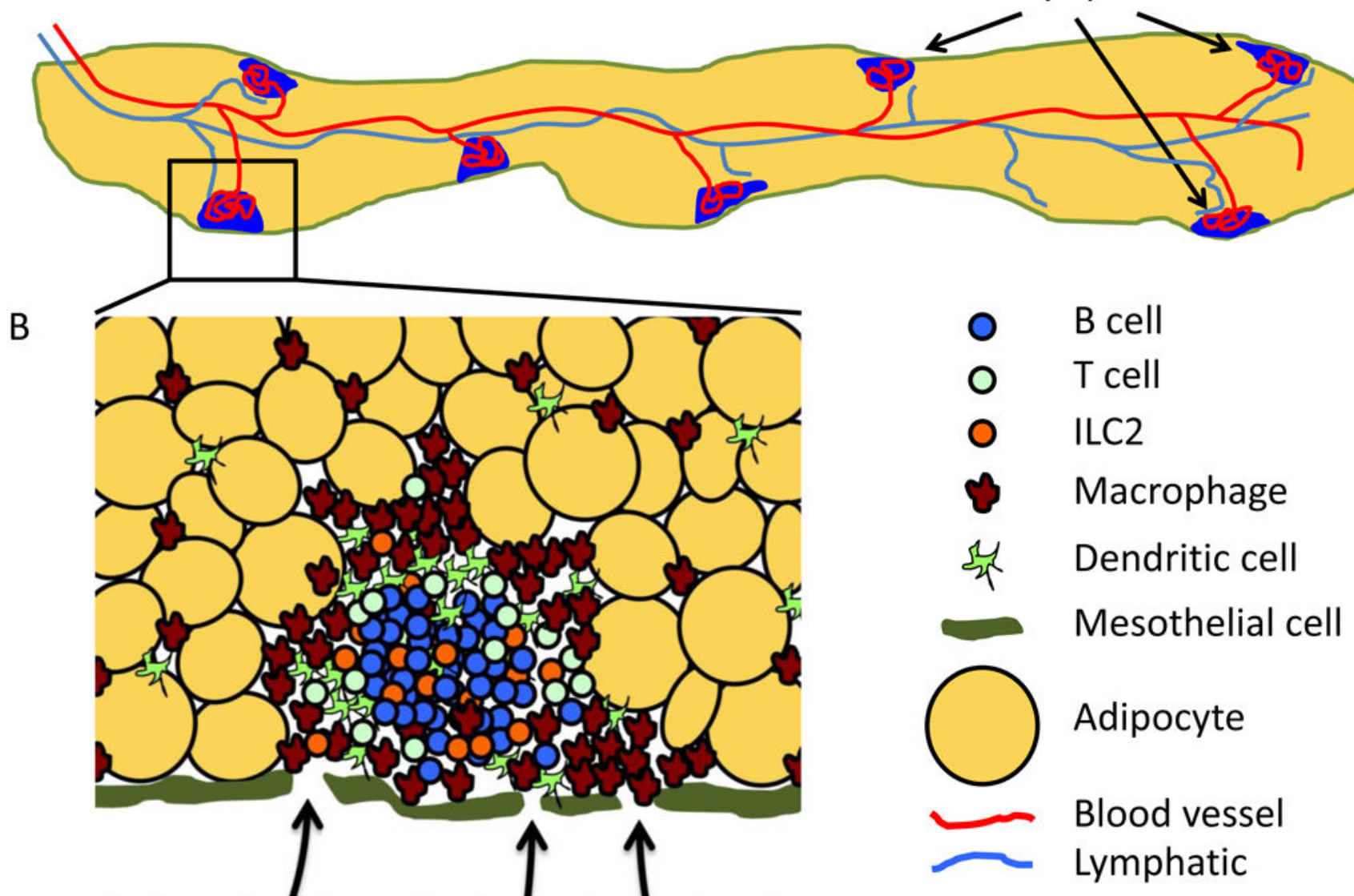

\section{Cells and antigens in the peritoneal cavity}

Figure 1. Structure of Milky Spots in the Omentum

A. Schematic of whole omentum in mice. The omentum is a thin strip of fat (yellow) that is covered by a layer of mesothelial cells (green). Milky spots (blue) are located just beneath the mesothelial layer embedded between adipocytes. The omentum is well vascularized with an extensive network of capillaries (not shown) running between the adipocytes that connect to a large central blood vessel (red). Blood vessels also connect to the milky spots and form a glomerulus-like knot of blood vessels in the lymphoid clusters. A large central lymphatic vessel ((light blue) also runs down the center of the omentum and branches from this vessel lead to milky spots as well as to areas of the omentum that lack milky spots. The human omentum is much larger and resembles an apron hanging in front of the abdomen, but also contains milky spots. B. Structure of milky spot. Milky spots are loose collections of leukocytes embedded between adipocytes (yellow) just beneath the mesothelial layer (green). B cells (blue) form a central cluster, whereas macrophages (brown) and dendritic cells (light green) tend to accumulate around the outside of the milky spot and are also found individually throughout the omentum. T cells (green circles) and ILCs (orange) can be intermixed with the B cells or may cluster around blood vessels (not shown). Cells and antigens are passively collected from the peritoneal cavity through fenestrations in the mesothelial layer by fluid flow or may be actively carried by phagocytic cells like 
macrophages. Cells can also enter the milky spots from the blood through HEVs (not shown). 